\title{
Uso de suero de leche líquido en la alimentación de cuyes (Cavia porcellus) en la etapa de crecimiento y engorde
}

\author{
Cornelio Rosales J. ${ }^{1}$, Fabiola León $C^{1}{ }^{1}$, María Fajardo F. $^{2}$, Xavier Jara G. ${ }^{2}$ \\ ${ }^{1}$ Facultad de Ciencias Agropecuarias, Universidad de Cuenca, Avenida 12 de Octubre y Diego de \\ Tapia, Cuenca, Ecuador. \\ ${ }^{2}$ Tesista, Universidad de Cuenca.
}

Autor para correspondencia: cornelio.rosales@ucuenca.edu.ec

Fecha de recepción: 2 de mayo 2014 - Fecha de aceptación: 22 de septiembre 2014

\section{RESUMEN}

Una ración de $25 \%, 50 \%, 75 \%$ y $100 \%$ de suero de leche líquido en la alimentación de cuyes machos y hembras, se ensayó frente a un control de $0 \%$ de suero de leche líquida en la dieta diaria durante el período de crecimiento y engorde. La población estuvo conformada por 150 animales, distribuidos en un diseño de bloques al azar con tres repeticiones. La dieta diaria consistía en diferentes niveles de suero de leche líquido, un paquete de alimentos presupuestados semanalmente de concentrados comerciales de alfalfa. Los resultados revelaron una correlación positiva entre la dosis de suero líquido en la dieta y el peso de cuyes machos y hembras, con el efecto más positivo y significativo $(p<0,5)$ en el tratamiento $100 \%$ para machos y $75 \%$ para las hembras. La relación beneficio/costo fue mayor en los tratamientos 75 y $100 \%$; 1,37 frente a 1,10 en el control. Degustación, en base a las variables de color, olor y terneza, marcó el mejor para un suplemento de suero líquido de 50\%; sabor obtuvo la mayor puntuación de un suplemento $100 \%$ de suero líquido; y las variables presentación y aceptación anotó mejor en un suplemento 75 y $100 \%$.

Palabras clave: Cuyes, suero de leche, peso, proteína, degustación.

\begin{abstract}
A ration of $25 \%, 50 \%, 75 \%$ and $100 \%$ liquid whey in the feeding of male and female guinea pigs was tested versus a control of $0 \%$ liquid whey in the daily diet during the period of growth and fattening. The population consisted of 150 animals, distributed in a random block design with three replications. The daily diet consisted of different levels of liquid whey on top of a weekly budgeted food package of commercial concentrate and alfalfa. Results revealed a positive correlation between the dosage of liquid whey in the diet and the weight of male and female guinea pigs, with the most positive and significant effect $(\mathrm{p}<0,5)$ in treatment $100 \%$ for males and $75 \%$ for females. The benefit/cost ratio was highest in the treatments 75 and $100 \%$; 1,37 versus 1,10 in the control. Degustation, based on the variables color, smell and tenderness, scored best for a liquid whey supplement of 50\%; flavor scored highest for a $100 \%$ supplement of liquid whey; and the presentation and acceptance variables scored best at a 75 and $100 \%$ supplement.
\end{abstract}

Keywords: Guinea pigs, whey, weight, protein, tasting. 


\section{INTRODUCCIÓN}

La producción de cuyes (Cavia porcellus) desde siempre ha constituido una fuente importante de alimento para el hombre andino (de Zaldivar, 2007), especialmente de aquellos estratos sociales vulnerables. En los últimos años, la relevancia de la especie como alimento para la nutrición humana en los países como Ecuador, Perú, Colombia y en aquellos en los que no es considerada fuente alimenticia ha crecido ante el incremento de la demanda de proteína animal. El reto actual de la explotación de cuyes es optimizar su sistema dinámico zootécnico de producción muchas veces caracterizado por la escasez o baja calidad del forraje usado, obligando al criador a buscar alimentos alternativos que complementen la dieta, sin incrementar los costos de producción (de Zaldivar, 1997; Maita, 2002).

La crianza de cuyes en los países andinos, incluido el Ecuador, se realiza mayoritariamente a un nivel familiar y familiar-comercial. El primero caracterizado por ser la familia la base de insumos y mano de obra, los animales son criados casi exclusivamente para el consumo familiar o como fuente de ingresos emergentes. Este tipo de crianza no permite obtener niveles buenos de reproducción, crecimiento y engorde; además, son de poco control sanitario y los insumos alimenticios empleados son por lo general forrajes, residuos de cosechas y de cocina. La crianza familiar-comercial, es un método familiar organizado, los productores invierten recursos económicos en infraestructura, siembra de forrajes, dotación de sobrealimento, adquisición de pie de cría mejorado y usa mano de obra familiar; se mantienen entre 100 y 500 cuyes, y un máximo de 150 reproductoras, se maneja en un mismo galpón, agrupados por edades y sexo, y se mantiene la producción de forraje anexa a la granja (Guacho, 2009).

El suero de leche líquido es un subproducto de interés para la nutrición animal por su composición y calidad de proteína (grasa $1,04 \%$, lactosa $5,51 \%$, proteína $1,06 \%$, calcio $23,3 \mathrm{mg} 100 \mathrm{~g}^{-1}$, fósforo $16,9 \mathrm{mg} 100 \mathrm{~g}^{-1}$ y magnesio $16,3 \mathrm{mg} 100 \mathrm{~g}^{-1}$ ) (Faría y col., 2002). La ventaja del suero de leche reside especialmente en la composición de las fracciones proteicas y minerales, así como en su contenido de vitaminas hidrosolubles (Calderón y Cazares, 2008). Maita (2002) probó dietas compuestas con diferentes porcentajes de suero de leche en sustitución del agua de bebida en cuyes en etapa de gestación y lactancia sin encontrar rechazo, pero sí efectos positivos en ganancia de peso $(75 \%$ lactosuero $+25 \%$ agua) de las madres; aunque los resultados sobre peso de crías al nacimiento y destete fueron menores por el mayor número de crías obtenidas al adicionar lactosuero. Valencia (1992) de igual forma probó el uso de suero de leche en la dieta de cuyes en recría-engorde pero considerando un concentrado con $14 \%$ de proteína, sin alcanzar los pesos exigidos por el mercado.

La suplementación con bloques nutricionales a base de alfarina y paja de cebada en diferentes dosis en donde el lactosuero entró como componente estructural de la dieta fue probado en las etapas de crecimiento y engorde de cuyes peruanos mejorados de 30 días de edad (Bacuilima, 2002). Se encontró que no existe diferencias estadísticas entre tratamientos en cuanto a la ganancia de peso, excepto en el período de los primeros 15 días iniciales de experimentación, en donde la alfalfa fresca promueve la mayor ganancia de peso. De los resultados se desprende que existe diferencias de comportamiento de los tratamientos de acuerdo a como avanza los días de experimentación. Las mayores diferencias se encuentran sobre la variable costo (Calderón y Cazares, 2008). La adición de suplementos alimenticios se observan beneficiosos sobre la ganancia de peso en cuyes en crecimiento con alimentación a base de alfalfa, posiblemente por incrementarse el nivel de energía en la dieta total. Es así que la adición de harina de cebada como suplemento mejora significativamente la ganancia de peso, consumo, índice de conversión, relación beneficio-costo y, consecuentemente, la edad de saca, esto contrastado con el uso de forraje sin suplemento (Quintana y col., 2013).

La presente investigación tuvo el objetivo de evaluar el efecto de diferentes porcentajes de suero lácteo adicionado al agua de bebida como complemento a la dieta de cuyes en las etapas de crecimiento y engorde en relación a su aceptabilidad y ganancia de peso y su relación con costos de producción y palatabilidad de la carne de cuy. Se utilizó los mismos porcentajes de suero probados por Maita (2002), pero en nuestro caso se dirigió a probar sobre animales en etapa de crecimiento y engorde, encontrándose respuestas diferentes en los niveles probados de acuerdo al sexo. 


\section{MATERIALES Y MÉTODOS}

\section{1. $\quad$ Materiales}

La investigación experimental tuvo una duración de 75 días en la que se utilizó 150 cuyes (75 machos y 75 hembras) de 15 días de edad con un peso inicial promedio de $268 \mathrm{~g}$ en machos y $270 \mathrm{~g}$ en hembras para iniciar la etapa de crecimiento y posterior engorde. Se evaluaron 5 tratamientos para hembras y machos, cada uno conformados por 75 animales, cada tratamiento tuvo 3 repeticiones con 5 cuyes cada una, tanto para machos como para hembras. Durante los 75 días de experimentación se tuvo la mortalidad de 5 animales.

\subsection{Métodos}

La investigación se realizó en un galpón ubicado en Challuabamba, perteneciente a la parroquia de Nulti, cantón Cuenca, provincia del Azuay, a una altitud de 2387 m.s.n.m., una temperatura máxima de $26^{\circ} \mathrm{C}$ y mínima de $13^{\circ} \mathrm{C}$ (starMEDIA, 2014). Los animales fueron colocados en un galpón apropiado usando el método de crianza en pozas al piso, cada una de ellas rotuladas. Para la implementación se tomaron todas las medidas de bioseguridad tanto en infraestructura como en comederos y bebederos a utilizarse.

Los tratamientos de suero de leche que se probaron fueron: $25 \%$ de suero $+75 \%$ de agua, $50 \%$ de suero $+50 \%$ de agua, $75 \%$ de suero $+25 \%$ de agua, $100 \%$ de suero de leche y $0 \%$ (testigo) de suero. La dosis de suero de leche líquido se aumentó en $5 \mathrm{ml}$ por semana, de $50 \mathrm{ml}$ por día en la primera semana a $100 \mathrm{ml}$ por día en la última semana del experimento de alimentación. El lactosuero utilizado fue analizado encontrándose un contenido de proteína bruta del 5\%, lactosa de 4,7\% y 0,2\% de grasa en base húmeda. Esta información fue utilizada como referencial ya que el propósito de la investigación no fue valorar porcentajes de proteína en dietas sino la incorporación del suero de leche como fuente de agua y suplemento nutricional complementario a la dieta.

En promedio la composición del forraje utilizado fue: proteína cruda $19,7 \%$, grasa cruda $0,3 \%$ y fibra cruda $28,7 \%$. El concentrado comercial usado tuvo la siguiente composición en base fresca: proteína cruda $17,2 \%$, fibra cruda $12,75 \%$, energía digestible $2650 \mathrm{Kcal} \mathrm{kg}^{-1}$. La cantidad de alfalfa y concentrado provista respondió a las cantidades tradicionalmente utilizadas por los productores de cuyes de la región, por lo que se estructuró la siguiente estrategia: un consumo por animal de $50 \mathrm{~g}$ en el periodo hasta 25 días, de $100 \mathrm{~g}$ después hasta 51 días, y de $200 \mathrm{~g}$ en el último periodo hasta el fin de la experimentación. Análogamente, la administración de concentrados varió en función de la edad de la siguiente manera: un consumo de concentrado comercial por animal de $25 \mathrm{~g}$ las dos primeras semanas, con un aumento de $5 \mathrm{~g}$ cada dos semanas, hasta $50 \mathrm{~g}$ en el último periodo, la semana 11 (correspondiente a los días 85 a 90).

\subsection{Toma de datos}

Con relación al peso y su comportamiento se usó la unidad de gramos, a través de una balanza digital con capacidad de $5 \mathrm{~kg}$ y 1 gramo de precisión. El peso inicial (15 días de edad) fue registrado individualmente al ingreso de los animales. Después fue registrado el peso global de los cincos animales en cada repetición, periódicamente cada 15 días hasta la edad de 90 días, en el que se tomó el peso final. Con los datos obtenidos se obtuvo promedios por repetición, tratamiento y por periodo. La ganancia de peso se determinó por diferencia entre el peso inicial y el final en los diferentes periodos. El consumo diario de alfalfa, concentrado y suero de leche líquido se determinó por diferencia entre lo consumido y lo no consumido por el total de animales que conformaron la unidad experimental (repetición), la sumatoria de datos diarios a lo largo del periodo experimental dio el consumo total de cada uno de los alimentos. No fue objeto de análisis el consumo diario o periódico.

La variable mortalidad se determinó con la ratio entre el total de animales muertos y el total de animales vivos en porcentaje: y la variable conversión alimenticia se evaluó con el ratio entre el consumo de alimento en g sobre la ganancia de peso en g. Para evaluar las características organolépticas se sacrificaron 2 cuyes por tratamiento, cada uno de ellos dividido en piezas de las que 
se valoró las siguientes características: color, olor, sabor, terneza, presentación y aceptación de la carne del cuy. Fueron 10 personas adultas de los dos sexos que tuvieron acceso a las piezas de cuy preparado de manera tradicional asada al carbón y presentadas en platos diferentes de acuerdo al tratamiento al que pertenecían y ordenados al azar. La información se procesó en un formulario individual preparado para el propósito.

\subsection{Diseño experimental}

El tipo de diseño que se aplicó en la investigación fue un diseño de bloques al azar, con arreglo factorial $2 \times 5$, en donde el factor A estuvo constituido por el sexo (machos y hembras) y el factor B por los diferentes niveles de suero de leche líquido. El número de tratamientos fue de 5 para hembras y 5 para machos, cada uno con 3 repeticiones, y 5 animales por repetición. Para el procesamiento de datos y análisis estadístico se utilizó el software SPSS, versión 22.0. Se aplicó el análisis unidireccional de la varianza (ANOVA) para probar los efectos de los diferentes tratamientos sobre los factores medidos; cuando se encontró una variación significativa en el análisis de varianza se realizó la prueba de rangos múltiples de Duncan para la comparación de medias. Además, se aplicó la regresión y correlación del efecto de los niveles de suero de leche con respecto al peso final.

\section{RESULTADOS}

\subsection{Peso final}

Para el peso de machos y hembras a los 90 días, se obtuvo un valor $\mathrm{p}=0,000$ lo que indica que existe diferencia significativa entre los pesos de los tratamientos. El peso promedio final más alto se obtuvo con el tratamiento $100 \%$ (suero puro) en machos y $75 \%$ para hembras con un peso promedio de $1027 \mathrm{~g}$ y $1018 \mathrm{~g}$, respectivamente. Los pesos finales mencionados representaron un incremento de $759,7 \mathrm{~g}$ en machos y de $747 \mathrm{~g}$ en hembras comportándose estas dos como las mejores opciones. Los menores pesos finales se alcanzó con el tratamiento testigo (0\%) tanto para machos como para hembras con pesos promedios de 908,3 g y 905,3 g, respectivamente (ver Tablas 1 y 2).

Tabla 1. Evolución del peso promedio de machos en función del tratamiento de suerode leche líquido y el tiempo.

\begin{tabular}{cccccc}
\hline \multirow{2}{*}{ Tiempo } & \multicolumn{5}{c}{ Concentración de suero líquido de leche en la dieta } \\
\cline { 2 - 6 } & $0 \%$ & $25 \%$ & $50 \%$ & $75 \%$ & $100 \%$ \\
\hline Inicial & $267.3 \mathrm{a}$ & $268.7 \mathrm{a}$ & $267.7 \mathrm{a}$ & $267.7 \mathrm{a}$ & $267.0 \mathrm{a}$ \\
15 días & $321.3 \mathrm{a}$ & $321.7 \mathrm{a}$ & $322.7 \mathrm{a}$ & $325.0 \mathrm{a}$ & $329.0 \mathrm{a}$ \\
30 días & $498.3 \mathrm{a}$ & $508.7 \mathrm{ab}$ & $513.3 \mathrm{ab}$ & $518.0 \mathrm{~b}$ & $520.7 \mathrm{~b}$ \\
45 días & $630.7 \mathrm{a}$ & $648.7 \mathrm{ab}$ & $676.7 \mathrm{ab}$ & $683.7 \mathrm{ab}$ & $705.0 \mathrm{~b}$ \\
60 días & $749.3 \mathrm{a}$ & $778.0 \mathrm{~b}$ & $809.7 \mathrm{c}$ & $864.3 \mathrm{~d}$ & $883.3 \mathrm{~d}$ \\
75 días & $845.3 \mathrm{a}$ & $867.7 \mathrm{a}$ & $913.7 \mathrm{~b}$ & $959.3 \mathrm{c}$ & $988.3 \mathrm{c}$ \\
90 días & $908.3 \mathrm{a}$ & $922.7 \mathrm{~b}$ & $980.7 \mathrm{c}$ & $1000.3 \mathrm{~d}$ & $1026.7 \mathrm{e}$ \\
\hline
\end{tabular}

\subsection{Consumo de suero de leche líquido y forraje}

El consumo de suero líquido de leche tuvo una relación directa; es decir que de acuerdo a como se incrementa la dosis se incrementa su consumo, por lo que se puede inferir que a las dosis estudiadas no se produce ningún efecto de rechazo o problema de aceptabilidad por parte de los animales, habiéndose registrado el mayor consumo total promedio en T5 (100\%), en machos $4747 \mathrm{ml}$ y en hembras de $4656 \mathrm{ml}$. En cuanto al consumo de forraje el comportamiento fue inverso; es decir, a menor porcentaje de suero provisto mayor consumo de forraje, excepto en el tratamiento $75 \%$ para hembras en el cual se dio un menor consumo con relación al tratamiento $100 \%$. 
Tabla 2. Evolución del peso promedio de hembras en función del tratamiento de suero de leche líquido y el tiempo.

\begin{tabular}{cccccc}
\hline \multirow{2}{*}{ Tiempo } & \multicolumn{5}{c}{ Concentración de suero líquido de leche en la dieta } \\
\cline { 2 - 6 } & $0 \%$ & $25 \%$ & $50 \%$ & $75 \%$ & $100 \%$ \\
\hline Inicial & $269.7 \mathrm{a}$ & $270.3 \mathrm{a}$ & $271.0 \mathrm{a}$ & $271.3 \mathrm{a}$ & $267.3 \mathrm{a}$ \\
15 días & $288.3 \mathrm{a}$ & $320.3 \mathrm{a}$ & $323.7 \mathrm{a}$ & $325.0 \mathrm{a}$ & $321.0 \mathrm{a}$ \\
30 días & $437.0 \mathrm{a}$ & $456.3 \mathrm{ab}$ & $518,7 \mathrm{ab}$ & $563.0 \mathrm{~b}$ & $515.0 \mathrm{ab}$ \\
45 días & $609.3 \mathrm{a}$ & $618.7 \mathrm{a}$ & $677.0 \mathrm{~b}$ & $687.7 \mathrm{~b}$ & $713.7 \mathrm{~b}$ \\
60 días & $721.0 \mathrm{a}$ & $733.7 \mathrm{a}$ & $819.7 \mathrm{~b}$ & $875.7 \mathrm{c}$ & $836.0 \mathrm{~b}$ \\
75 días & $853.3 \mathrm{a}$ & $888.3 \mathrm{ab}$ & $917.7 \mathrm{bc}$ & $978.7 \mathrm{~d}$ & $942.7 \mathrm{~cd}$ \\
90 días & $905.3 \mathrm{a}$ & $929.7 \mathrm{~b}$ & $976.0 \mathrm{c}$ & $1018.3 \mathrm{e}$ & $995.3 \mathrm{~d}$ \\
\hline
\end{tabular}

Usando el análisis de la varianza (ANOVA) para contrastar cómo las variables de los 5 tratamientos $(0 \%, 25 \%, 50 \%, 75 \%$ y $100 \%)$ son afectados por el nivel de consumo de suero de leche en machos y hembras se obtuvo un valor de $\mathrm{p}<0,05$ que significa que las diferencias entre los resultados son significativos; es decir, que los tratamientos difieren con respecto a las variables analizadas (ver Tablas 1 y 2). Según la prueba de Duncan, al 5\% se registró el mayor consumo en los machos y hembras en el tratamiento al 100\%, con un promedio de 4747 y $4656 \mathrm{ml}$ (Fig. 1). El menor consumo se observa en el tratamiento al $0 \%$, con un promedio de 2748 y $3215 \mathrm{ml}$, respectivamente, por machos y hembras. De igual forma, para consumo de forraje en machos se registró el mayor consumo para el tratamiento al $0 \%$, con un promedio de $8169 \mathrm{~g}$, y el menor consumo en el tratamiento al 100\% (suero puro) con $8136 \mathrm{~g}$. En hembras se registró el mayor consumo para el tratamiento al $0 \%$ con un promedio de $8093 \mathrm{~g}$, y el menor consumo en el tratamiento al $75 \%$ con $8059 \mathrm{~g}$.
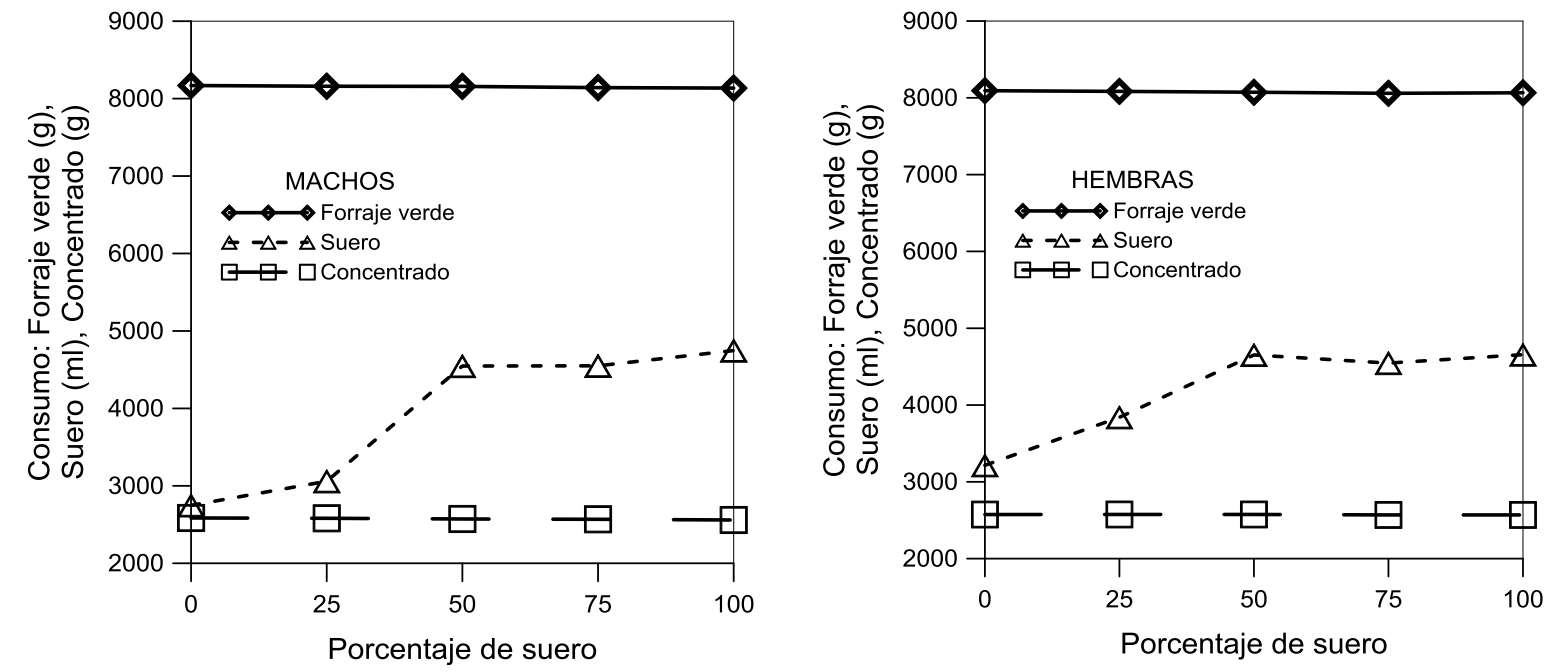

Figura 1. Consumo de forraje verde, dieta de suero líquido y concentrado, de machos (izquierda) y hembras (derecho).

\subsection{Consumo de concentrado comercial}

El consumo de concentrado comercial no demostró diferencias marcadas entre los tratamientos teniendo un comportamiento igual al de consumo de forraje; es decir, una relación inversa a la concentración de suero de leche. Considerando el análisis de varianza en el que se contrastó los 5 tratamientos $(0 \%, 25 \%, 50 \%, 75 \%$ y $100 \%)$ en la variable consumo de concentrado en machos y hembras, se obtuvo un valor de $\mathrm{p}>0,05$ que determinó que la diferencia en el consumo de concentrado comercial no es significativa; es decir, los tratamientos son homogéneos con respecto a esta variable. 


\subsection{Conversión alimenticia}

La conversión alimenticia se muestra más eficiente en la dieta al 100\% (suero puro) para machos con un índice de 4,51 y al 75\% de suero para hembras cuyo valor es 4,52. El testigo (0\% suero) obtuvo el índice de conversión de 4,8 resultando ser el menos eficiente.

\subsection{Resultados del análisis de regresión y de correlación}

El análisis de regresión examinó la mejor relación entre el peso y el consumo de suero de leche, mientras que la correlación explica el grado de asociación entre ambas variables. Al realizar la regresión para las variables antes mencionadas, se obtuvo un coeficiente de determinación que indica, que el 90,7\% de las variaciones en el peso de los machos y el 77,4\% de las variaciones en el peso de hembras se debe a las variaciones de concentración de suero de leche, lo que significa que al aumentar $1 \mathrm{ml}$ en el consumo de suero incrementará en promedio $0,05 \mathrm{~g}$ en el peso de los machos y $0,06 \mathrm{~g}$ en el peso de las hembras (Fig. 2). Al comparar las variables peso de los machos y hembras con el consumo de suero, se obtuvo un coeficiente de correlación de 0,952 y 0,880 respectivamente, lo que explica el grado de asociación entre las dos variables. En otras palabras, existe una correlación muy positiva para machos y positiva considerable para hembras.
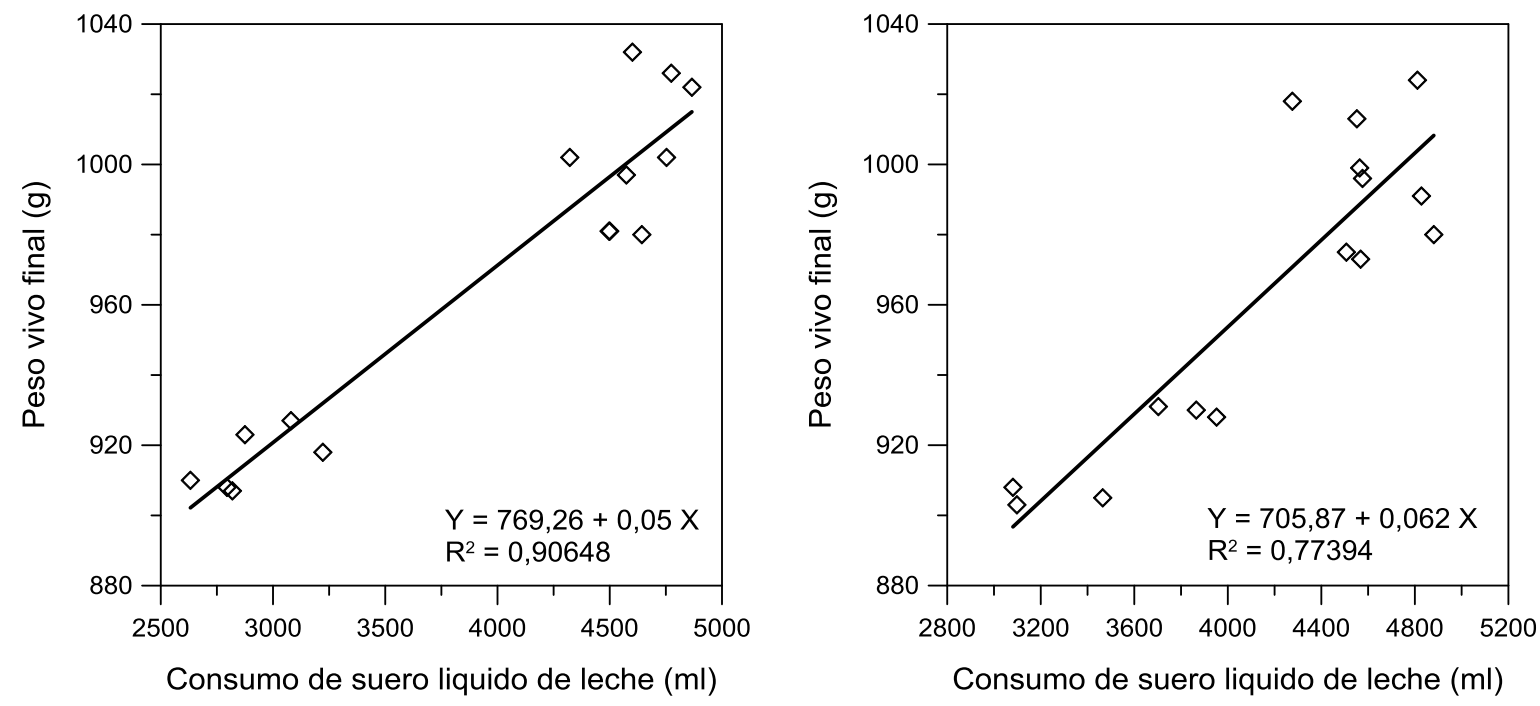

Figura 2. Correlación de peso machos (izquierdo) y hembras (derecho) con consumo de suero de leche.

\subsection{Mortalidad y Prueba de degustación}

En cuanto a la mortalidad, se obtuvo un porcentaje del 3,33\%; los animales muertos fueron por causas ajenas a la investigación debidas a condiciones inadecuadas de forraje al contener hierbas indeseables. Este porcentaje es igual al obtenido por Bacuilima (2002) en una investigación similar. Para las variables color, olor y terneza el mejor tratamiento fue al $50 \%$, definido por el $70-80 \%$ de degustadores, el peor tratamiento fue al $0 \%$. Para la variable sabor el tratamiento al $100 \%$ fue el mejor calificado, seguido de los tratamientos $75 \%$ y 50\%; finalmente las variables presentación y aceptación fueron mejores en los tratamientos al 75 y $100 \%$ respectivamente.

\section{DISCUSIÓN}

Contrastados los valores obtenidos en la presente investigación en cuanto al peso final de los animales a los noventa días (machos $1027 \mathrm{~g}$ y hembras 1018 g) se muestran superiores a los reportados en 
investigaciones similares como la de Maita (2002), quien en su estudio sobre uso del lactosuero en etapa de gestación y lactancia expresa que este residuo de la industrialización de la leche tiene un efecto positivo sobre el peso ya que alcanzó los mayores promedios en las madres que consumieron las mayores dosis. Valencia (1992) en su investigación realizada en la misma etapa de crianza pero con diferente dieta (balanceado 14\% proteína) consiguió pesos finales de 784,5 g en los cuyes alimentados con 75\% de suero de leche. Morocho (1989) al evaluar los diferentes niveles de kikuyo (Pennisetum clandestinum) más alfalfa y balanceado con 18,40\% de proteína, determinó pesos de 779 g. De manera similar, Bacuilima (2002) con el uso de bloques nutricionales en cuyes de engorde encontró un peso promedio de $806 \mathrm{~g}$. Todas estas investigaciones evaluadas a los 90 días de edad. El efecto positivo sobre la ganancia de peso puede estar determinado por la cantidad (considerando que proviene de quesería rural) y el alto valor biológico de la proteína existente en el lactosuero, lo que le hace altamente digestible; además de su contenido de arginina, que es uno de los 20 aminoácidos que se encuentran formando parte de las proteínas, un aminoácido condicionalmente esencial, importante para el desarrollo.

El consumo de suero en la investigación tuvo una relación directa; es decir, que a mayor concentración mayor consumo (100\% lactosuero 3,22 g MS día ${ }^{-1}$, al 75\% con 3,15 g MS día ${ }^{-1}$, al 50\% con 3,11 g MS día ${ }^{-1}$ y al 25\% con 2,4 g MS día ${ }^{-1}$ (g MS = gramo materia seca). Esta realidad está determinada porque no existió, a ninguna dosis, problema de rechazo en el consumo, lo que es corroborado por Maita (2002), quien evidenció igual situación. Similar comportamiento encontró Valencia (1992) quien menciona que conforme los niveles fueron incrementados, el consumo fue mayor, observándose que el mayor consumo diario fue en el nivel 100\% con 3,61 g el que difirió de $75 \%$ con $2,36 \mathrm{~g}$ y éste de los tratamientos 50 y $25 \%$ con 1,24 y $0,59 \mathrm{~g}$ respectivamente.

Una relación inversa se encontró entre los componentes de la dieta, es así que a mayor dosis de suero de leche provisto, el consumo de forraje y concentrado disminuyó. El consumo total de materia seca encontrado fue superior en los tratamientos con mayor dosis de lactosuero, lo que coincide con Valencia (1992) que encontró igual realidad en los niveles 50, 75, y 100\% con una media de 44,61 g día $^{-1}$, similar a los promedios encontrados en el presente estudio; 50,7 y 50,6 g día ${ }^{-1}$ en machos y hembras respectivamente. Estos valores de consumo total no se alejan de valores observados por Macao (1989), Morocho (1989) y Padilla (1990), quienes reportan consumos de 47, 49, y $46 \mathrm{~g} \mathrm{día}^{-1}$, obtenidos al estudiar varios niveles de contenido ruminal, diferentes niveles de kikuyo más alfalfa balanceado, y diferentes niveles de gallinaza en el balanceado más alfalfa. La mejor conversión alimenticia fue similar para machos y hembras $(4,51 \mathrm{y} 4,52)$ aunque en tratamientos diferentes de $100 \%$ y $75 \%$ de suero de leche.

El uso de suero lácteo como opción para complementar la dieta de cuyes en etapa de engorde mejora las características organolépticas de la carne, muestra una relación beneficio/costo superior a 1 , siendo la más alta para los tratamientos al 75 y $100 \%$ con 1,37 frente al testigo 1,10 ; lo que nos indica una mayor rentabilidad dentro de la explotación de cuyes, lo que significaría ingresos adicionales para aquellas familias que sustentan o complementan sus ingresos en esta línea productiva pecuaria (Ruiz, 2006). Aspecto importante de mencionar es que el lactosuero en los actuales momentos se ha convertido en un problema para la salud ambiental. Esto debido a que el exceso de producción de este residuo proveniente de la industria lechera y quesería rural no es procesado, por lo que es vertido ya sea a cauces naturales de agua o alcantarillado sanitario con la consiguiente contaminación al suelo y/o fuentes de agua. Su uso rutinario en la producción animal disminuyendo el volumen excedentario significaría contribuir de manera práctica a la sostenibilidad de los recursos naturales y a la salud ambiental (Denicia y col., 2009).

\section{CONCLUSIÓN}

El uso de suero de leche líquidoes una excelente opción nutricional para favorecer la ganancia de peso en cuyes en etapa de cría y engorde, alcanzando peso animal de mercado a una edad adecuada y mejorando las características organolépticas. Su inclusión al agua de bebida al $75 \%$ en hembras y $100 \%$ en machos se muestran como los mejores para alcanzar los mayores pesos, sin encontrarse 
ningún efecto de rechazo ni tampoco efectos adversos en la salud animal que conlleven a mortalidad de animales. Se encontró que existe una relación inversa entre porcentaje de suero, consumo de balanceado y forraje; es decir, que a mayor porcentaje de suero adicionado a la dieta líquida disminuye el consumo de gramos de balanceado y forraje, lo que implica menores costos de producción que genera una relación beneficio/costo superior a 1. El uso de lactosuero resulta pertinente tanto desde el punto de vista productivo como ambiental ya que genera efectos positivos desde lo económico y disminuye los excedentes de este residuo generados por la industria lechera formal y tradicional que son descargados hacia el ambiente.

\section{BIBLIOGRAFÍA}

Bacuilima, W., 2002. Influencia de la uitilización de bloques nutricionales en cuyes de engorde. Tesis de pregrado, Medicina Veterinaria y Zootecnia, Facultad de Ciencias Agropecuarias, Universidad de Cuenca, Cuenca, Ecuador, 180 pp. Descargado de http://dspace.ucuenca.edu.ec/handle/ $123456789 / 17903$ el 15 de febrero 2014.

Barba, V., J. Calispa, A. Minda, M. Mosquera, 2010. Biodegradación de suero lácteo de quesería. Proyecto de Microbiologia Industrial, Escuela de Bioquímica y Farmacia, Facultad de Ciencias Químicas, Universidad Central del Ecuador, Quito, Ecuador, 12 pp.

Calderón, G.E., R.R. Cazares, 2008. Evaluación del comportamiento productivo de cuyes (Cavia porcellus) en las etapas de crecimiento y engorde, alimentados con bloques nutricionales en base a paja de cebada y alfarina. Tesis Ingeniero Agroindustrial, Escuela de Ingeniería Agroindustrial, Facultad de Ingeniería en Ciencias Agropecuarias y Ambientales, Universidad Técnica del Norte, Ecuador, 137 pp. Descargado de http://repositorio.utn.edu.ec/bitstream/123456789/465/1/ 03\%20AGI\%20220\%20TESIS.pdf el 13 de mayo de 2014.

Denicia, V., E., M. R. Castillo, M. Leticia, 2009. La industria de la leche y la contaminación del Agua. Ciencia y Cultura, 16(73), 27-31. Descargado de http://www.redalyc.org/ pdf/294/ 29411996004.pdf el 11 de marzo de 2014.

de Zaldivar, L.C.F., 1997. Producción de cuyes (Cavia porcellus). Estudio FAO Producción y Sanidad Animal, 138. FAO, Departamento de Agricultura, Rome.

de Zaldivar, L.C.F., 2007. Realidad y perspectiva de la crianza de cuyes en los países Andinos. Arch. Latinoam. Prod. Anim., 15(1), 223-228. Descargado de http://www.bioline.org.br/pdf?la07058 el 5 de marzo de 2014.

Faría, J.F., A.C. García, A. de Hernández, 2002. Efecto de la tecnología quesera sobre la composición del suero lácteo. Multiciencias, 2(2), 126-130. Descargado de http://www.redalyc.org/pdf/ 904/90420206.pdf el 12 de marzo de 2014.

Guacho, M.I., 2009. Valoración energética de diferentes tipos de balanceado utilizados en la alimentación de cuyes (Cavia porcellus). Tesis Ingeniero Zootecnista, Escuela de Ingeniería Zootécnica, Facultad de Ciencias Pecuarias, ESPOCH, Ecuador, 104 pp. Descargado de http://dspace.espoch.edu.ec/bitstream/123456789/1380/1/17T0895.pdf el 5 de mayo de 2014.

Macao, L., 1989. Evaluación del contenido ruminal en la alimentación de cuyes en recría. Tesis Ingeniero Zootecnista, Escuela de Ingeniería Zootécnica, Facultad de Ciencias Pecuarias, ESPOCH, Ecuador.

Maita, H., 2002. Suplementación con suero de leche en la alimentación de cuyes mejorados (Cavia porcellus Linnaeus), en gestación lactancia. Tesis de pregrado, Red de Bibliotecas Virtuales, Universidad Mayor de San Andrés, La Paz, Bolivia, 90 pp. Descargado de http://www.sidalc.net/cgi-bin/wxis.exe/?IsisScript=cidab.xis\&method=post\&formato $=$ $2 \&$ cantidad $=1$ \&expresion $=m f n=009846$ el 25 de abril de 2014 .

Morocho, S., 1989. Utilización de diferentes niveles de kikuyo más balanceado en la alimentación de cuyes peruanos mejorados. Tesis Ingeniero Zootecnista, Escuela de Ingeniería Zootécnica,

Facultad de Ciencias Pecuarias, ESPOCH, Ecuador. 
Padilla, A., 1990. Utilización de diferentes niveles de gallinaza (12, 16, 20 y 24\%) en la alimentación de cuyes peruanos mejorados durante las etapas de gestación, lactancia y crecimiento-engorde.

Tesis Ingeniero Zootecnista, Escuela de Ingeniería Zootécnica, Facultad de Ciencias Pecuarias, ESPOCH, Ecuador.

Quintana, E., R. Jiménez, F. Carcelén, F. San Martin, M. Ara, 2013. Efecto de dietas de alfalfa verde, harina de cebada y bloque mineral sobre la eficiencia productiva de cuyes. Rev. Inv. Vet. Perú, 24(4), 425-432.

Ruiz, D., 2006. Proyecto de Prefactibilidad para la exportación de cuyes faenados congelados Italia. Tesis de Ingeniero en Comercio Exterior e Integración, Escuela de Comercio Exterior e Integración, Facultad de Ciencias Económicas y Negocios, Universidad Tecnológica Equinoccial, Quito, Ecuador, 131 pp. Descargado de http://repositorio.ute.edu.ec/bitstream/123456789/ 7009/1/27847_1.pdf el 16 de febrero de 2014.

starMEDIA, 2014. Clima de hoy en Cuenca. Descargado de http://clima.starmedia.com/sudamerica/ ecuador/cuenca/ el 28 de abril de 2014.

Sotomayor, A., 2011. Estudio de factibilidad para la producción y exportación de carne de cuy (Cavia porcellus) para mercados de Estados Unidos y España. Tesis (Agroempresas), Colegio en Agricultura, Alimentos y Nutrición, Universidad San Francisco de Quito, Quito, Ecuador, 87 pp. Descargado de http://repositorio.usfq.edu.ec/bitstream/23000/1377/1/102338.pdf el 24 de abril de 2014.

Valencia, V. 1992. Utilización de suero de leche en la alimentación de cuyes en la etapa de crecimiento y engorde. Tesis Ingeniero Zootecnista, Escuela de Ingeniería Zootécnica, Facultad de Ciencias Pecuarias, ESPOCH, Ecuador.

van't Hooft, K. 2004. Gracias a los animales: análisis de la crianza pecuaria familiar en Latinoamérica, con estudios de caso en los valles y el altiplano de Bolivia. AGRUCO, CIGAC, ETC. Plural Editores, 480 pp. 